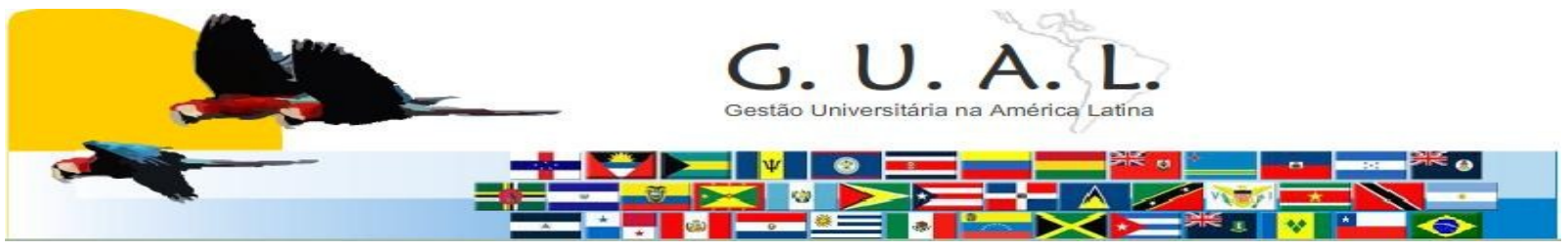

ISSN 1983-4535

\title{
EDUCAÇÃO A DISTÂNCIA E FORMAÇÃO DOCENTE: O SISTEMA UNIVERSIDADE ABERTA DO BRASIL COMO FORMA DE AMPLIAR O ACESSO À EDUCAÇÃOO SUPERIOR
}

\author{
Rafael Pereira Ocampo Moré, Bacharel \\ Universidade Federal de Santa Catarina - UFSC \\ rafael@cse.ufsc.br \\ Grace Tavares Vieira, Especialista \\ Coordenação de Aperfeiçoamento de Pessoal de Nível \\ Superior - CAPES \\ grace.vieira@capes.gov.br
}

Marcia Santiago de Araujo, Doutora

Universidade Federal do Rio Grande - FURG

marcia.araujo@riogrande.ifrs.edu.br

\author{
Thiago Luiz de Oliveira Cabral, Graduando \\ Universidade Federal de Santa Catarina-UFSC \\ cabral.thi@gmail.com \\ Alexandre Marino Costa, Doutor \\ Universidade Federal de Santa Catarina - UFSC \\ marino@cse.ufsc.br
}

\section{RESUMO}

A Lei de Diretrizes e Bases da Educação, de 1996, em seu artigo 80 estabeleceu a base legal para a operação da Educação a Distância - EaD em todas as instâncias. A importância desta lei advém da necessidade de se instituir com segurança, estabelecer parâmetros de funcionamento e qualidade e por fim, avaliar os diversos cursos de $\mathrm{EaD}$ por ele abrigado. Neste cenário surge a Universidade Aberta do Brasil - UAB como importante política de combate a deficiência na formação do docente nas unidades da Federação mais distantes dos grandes centros, entendendo a qualidade da formação docente é um ponto crítico para as sérias deficiências que assolam a educação básica brasileira. Diante disso, o objetivo do trabalho é analisar a UAB como alternativa de expansão e interiorização da educação, principalmente no tocante à formação docente.

Palavras-chave: Universidade Aberta do Brasil. Formação docente. Expansão. 


\section{INTRODUÇÃO}

No processo de universalização e democratização do ensino, especialmente no Brasil, que atualmente pode ser caracterizado por apresentar déficits de professores e desigualdades na oferta de cursos para formação docente em cada estado da federação, deve-se considerar a modalidade a distância como uma alternativa de ensino que ofereça soluções efetivas à crescente demanda professores que desejam uma formação de melhor qualidade e, consequentemente, propiciar um melhor ensino e oportunidades de acesso à educação superior aos alunos da rede básica.

$\mathrm{O}$ estímulo à oferta de cursos a distância, principalmente por parte do País após a criação da LDB/1996 - Lei de Diretrizes e Bases da Educação Nacional, fez surgir inúmeros cursos nessa modalidade, em especial aqueles voltados a formação docente, ou seja, professores carentes por uma formação acadêmica em nível superior.

Sendo assim, observa-se na $\mathrm{EaD}$ uma modalidade de ensino que pode contribuir diretamente com a formação de professores, e para isso duas metas foram definidas pelo País (ANDIFES, 2003): formar 50.000 professores, particularmente nos campos disciplinares que apresentam maior déficit; e criar um programa para titular 250.000 professores que atuem nas redes estaduais e municipal.

A princípio, verifica-se nestas metas um recorte quantitativo da educação para a expansão da sua oferta, contudo, deve-se valorizar o aspecto qualitativo da oferta de cursos a partir do aumento permanente da sua eficácia institucional e efetividade acadêmica e social e, especialmente, na promoção do aprofundamento dos compromissos e responsabilidade sociais das instituições da educação superior, por meio da valorização de sua missão pública, da promoção dos valores democráticos, do respeito à diferença e à diversidade, da afirmação da autonomia e da identidade institucional. (MEC, 2010a).

Por fim, percebe-se no fator qualidade na formação docente algo preocupante e que assola a educação básica brasileira, e entendendo que a formação desses professores é essencial para melhorar os índices da educação no país, será analisado o programa Universidade Aberta do Brasil (UAB) como proposta de formar profissionais, principalmente docentes.

Como proposta de facilitar o entendimento da Educação a Distância, como também da $\mathrm{UAB}$, serão apresentados os principais fundamentos da $\mathrm{EaD}$, a partir da contextualização da 
formação docente no cenário brasileiro, como também as principais políticas e legislações que norteiam as ações dos gestores e atores dessa modalidade de ensino.

\section{FORMAÇÃO DO DOCENTE}

O Brasil dispõe de uma carência na formação de professores, principalmente da educação básica, o que facilita o surgimento de políticas para ampliação na oferta de vagas na modalidade a distância (CASTRO; AQUINO; ANDRADE; 2009).

Uma das tendências da formação docente é a aquisição da competência para atuar na educação a distância, e esse é, talvez, o maior dos desafios para a adoção da EaD. De acordo com Sousa (1996), o aparato tecnológico necessário, ainda que de alto custo, pode ser facilmente adquirido. As barreiras estão na utilização eficaz desse aparato, sobretudo porque será necessário superar comportamentos e procedimentos tradicionais de ensino muito arraigados.

Desta forma, segundo Belloni (2006) o papel que o professor assume na EaD é o de parceiro do estudante no processo de construção do conhecimento, ou seja, acontece a transformação do professor de uma entidade individual em uma entidade coletiva, passando do atributo ensino para a aprendizagem.

A EaD tende a se tornar, cada vez mais, um elemento regular e necessário aos sistemas educativos, não somente para atender demandas específicas, mas também para estabelecer-se como função de grande importância, especialmente na educação da população adulta, pela demanda crescente aos cursos supletivos, formação continuada (lifelong learning) e pósgraduação (VIANNEY; BARCIA; LUZ, 2010).

Por um lado, esse contexto justifica a necessidade de uma formação mais consistente, contudo flexível para diagnosticar contextos e criativa para atuar adequadamente. Por outro lado, explicita que é uma profissão que implica saberes e que um processo formativo conseqüente demanda compreender como esses saberes são produzidos, integrados e utilizados na prática profissional (GUIMARÃES, 2004).

Uma aprendizagem apropriada das tecnologias da informação e comunicação, de modo a prover uma visão integral da disciplina, e pôr ênfase na “cultura da informação", é um elemento chave no êxito da preparação dos docentes (OILO, 1998).

Rev. GUAL., Florianópolis, v.4, n. 2, p.89-109, mai/ago. 2011 
Formar docentes para atuar em educação a distância é, também para Rezende (2010), a chave na implementação desta modalidade, principalmente quando se almeja mudança na qualidade na aprendizagem.

A mudança requerida é muito mais ampla e complexa e exige a compreensão pedagógica do processo de ensino e aprendizagem mediada, além de demandar o desenvolvimento de competências e habilidades específicas para os docentes e, porque não dizer, dos alunos. Em particular, a educação a distância exige que o docente saiba como transpor sua prática do real para o virtual (REZENDE, 2010).

Como exposto anteriormente, o uso das tecnologias de EaD implica uma mudança radical: do ensino centrado no professor, para o ensino centrado no aluno, o que, para muitos, parece uma diminuição do papel do professor, que passaria a ser um simples facilitador do processo de aprendizagem. Enfim, é o velho receio de que o professor seja substituído pelos meios, pela máquina (SOUSA, 1996).

De forma complementar, Pimenta e Anastasiou (2005) aportam que o professor neste cenário precisa refletir constante e coletivamente sobre o que se faz e isso é pôr-se na roda, é deixar-se conhecer, é expor-se. Também atribuem que é essencial considerar a importância da criatividade na solução de cada nova situação vivenciada. Nesse sentido, a aula - como momento e espaço privilegiado de encontro e de ações (seja presencial ou a distância) - não deve ser dada nem assistida, mas construída, feita pela ação conjunta de professores e alunos.

No Brasil, a primeira experiência de formação inicial de professores para o ensino básico por meio da educação a distância foi a licenciatura de pedagogia criada pela Universidade Federal do Mato Grasso, em 1995, com parceria do estado e municípios (Licenciatura Plena em Educação Básica: $1^{a} a ̀$ a $4^{a}$ série do $1^{o}$ grau). (BELLONI, 2006).

Sumarizando, para Rezende (2010), a questão principal para o professor online é a consciência de que ele deverá se preparar para desenvolver o conhecimento pedagógico (teorias de aprendizagem) que o capacite a atuar como instrumento auxiliar de ensino e aprendizagem, usando o computador como suporte; adquirir consistência teórica dos conteúdos disciplinares a serem ensinados; e aprender, gradativamente, a transpor sua prática do real ao virtual, realizando experiências concretas, dotado de postura reflexiva na e sobre a ação, não aceitando modelos prontos e acabados. 
Desta maneira, Moraes (2010) destaca que as implicações do novo paradigma na formação dos futuros professores para uma sociedade do conhecimento precisam ser cuidadosamente observadas visando um redimensionamento de seu papel. O modelo de formação dos professores pressupõe continuidade e visão de processo, não buscando um produto completamente acabado e pronto, mas um movimento permanente de "vir a ser". É um movimento de reflexão na ação e de reflexão sobre a ação.

Demonstrado a importância da formação docente, de maneira inicial e continuada, como forma de preparar os professores para atuar na rede básica de ensino, será apresentada a Educação a Distância como modalidade de ensino eficaz na formação de docentes.

\subsection{Educação a Distância}

A educação a distância é uma modalidade de ensino com características peculiares, a qual consiste na mediatização das relações entre professores e alunos. Nessa proposta de ensino, docentes ensinam e alunos aprendem em espaços e tempos distintos (LITWIN, 2001).

Uma das definições utilizadas para conceituar a educação a distância é a de Moore e Kearsley (2007, p. 2):

Educação a distância é o aprendizado planejado que ocorre normalmente em um lugar diferente do local de ensino, exigindo técnicas especiais de criação do curso e de instrução, comunicação por meio de várias tecnologias e disposições organizacionais e administrativas especiais.

Desta forma, podemos entender que as tecnologias constituem o meio de comunicação primordial nessa modalidade de ensino. Os recursos tecnológicos podem estabelecer a interação entre o aluno e a instituição de ensino, a exemplo do rádio, televisão, programas de computação áudio/videoconferência, videoteipes/videodiscos, entre outros (MOORE e KEARSLEY, 2007). A evolução tecnológica facilita a criação e o crescimento de novas propostas de aprendizagem na educação a distância, dando mais velocidade aos tratamentos de temas e aproximando docentes e alunos (LITWIN, 2001).

Para Niskier (2000, p. 49) a educação a distância pode ser conceituada através da ideia de que "[...] alunos e professores estão separados por uma certa distância e, às vezes, pelo tempo[...]", ou seja, para existir ensino, não haveria necessidade do professor em sala diante de um grupo de alunos. Sendo assim, os alunos ditam o ritmo de ensino e aprendizagem, ao 
passo que o papel dos professores na $\mathrm{EaD}$ é o de facilitador, orientador ou conselheiro (PETERS, 2004).

A educação a distância insere-se no compromisso de disseminar de melhor forma o conhecimento acadêmico a fim de atender setores mais amplos da população, constituindo para muitas pessoas uma valiosa oportunidade de estudo. Surgiu no contexto da educação como ferramenta para suprir o acúmulo de importantes necessidades educacionais (alfabetização, necessidade de ingresso precoce no mercado de trabalho, população isolada dos centros urbanos ou impossibilitada de ter acesso às formas convencionais de ensino) (LITWIN, 2001).

Os gestores educacionais têm se apropriado da $\mathrm{EaD}$ para atender certas necessidades, como por exemplo, o acesso crescente à oportunidades de aprendizado e treinamento, reduzir custos com educação, proporcionar capacitação, oferecer uma combinação entre trabalho e vida familiar e, proporcionar a atualização de competências (MOORE E KEARSLEY, 2007).

Em decorrência da grande expansão da EaD, tornou-se necessário criar medidas de regulação, supervisão e avaliação para cursos e instituições que utilizem essa modalidade, a fim de garantir a qualidade na oferta de ensino, e em nosso país, essa preocupação deu-se início com a consolidação da EaD através do Artigo 80 da Lei 9.394, de 20 de dezembro de 1996, intitulada como Lei de Diretrizes e Bases da Educação - LBD (BRASIL, 1996).

Os Decretos 2.494 e 2.561, ambos de 1998, regulamentaram o Artigo 80 da Lei 9.394, de 20 de dezembro de 1996, os quais foram posteriormente revogados pelo Decreto 5.622, de 19 de dezembro de 2005, sendo este, alterado pelo Decreto 6.303 de 12 de dezembro de 2007.

Retratado isso, comenta-se que são muitos os detratores da educação a distância, que a considerarem um método secundário, uma espécie de "último recurso" àqueles que não podem, por razões diversas, cursar o ensino presencial, e sendo assim, demonstra-se que, se de fato as origens da $\mathrm{EaD}$ podiam levar a tais conclusões, já não é o caso na atualidade. A utilização de diferentes métodos de ensino, recursos, ferramentas e tecnologias aplicados à otimização do ensino presencial faz pensar que a $\mathrm{EaD}$ preserva todas as qualidades de uma boa educação, o que permite às pessoas desenvolver suas capacidades cognitivas, sociais, emocionais, profissionais e éticas; e viver em sociedade, exercitando sua cidadania plena (MEC, 2010b).

Rev. GUAL., Florianópolis, v.4, n. 2, p.89-109, mai/ago. 2011 


\subsection{Políticas e Bases Legais da Educação a Distância}

O Brasil possui particularidades notáveis no que tange a educação, mormente nos desafios postos a levar a formação universitária a todos os recantos de um país com dimensões continentais e ocupação territorial desigual, com os grandes centros localizados no litoral. Por essas razões, a educação no Brasil precisa considerar novos cenários de estudos, com novos profissionais e novas atribuições, permitindo assim a reestruturação das instituições do ensino na tentativa de implementar um sistema de EaD (CASTRO; AQUINO e ANDRADE, 2009).

Para que se consiga vencer o considerável déficit educacional brasileiro, é necessário envidar esforços por meio de políticas e ações públicas de Estado. As políticas educativas brasileiras, públicas e privadas, sobretudo as que se voltam para a formação de professores, que, segundo Landim (1997, apud NISKIER 2000, p. 15), “[...] devem ser orientadas numa perspectiva de Educação Permanente, concebida como ato de educar para: abertura, novas experiências, novas maneiras de ser, novas idéias, o positivo, a mudança, o não previsível, a aprendizagem contínua."

Diante deste propósito, é regulamentada no Brasil a modalidade a distância, mais especificamente na Lei de Diretrizes e Bases da Educação (LDB) - Lei 9.394, de 20 de dezembro de 1996, que no seu art. 80 estabelece que (BRASIL, 2010d):

Art. 80. O Poder Público incentivará o desenvolvimento e a veiculação de programas de ensino a distância, em todos os níveis e modalidades de ensino, e de educação continuada.

$\S 1^{\circ}$. A educação a distância, organizada com abertura e regime especiais, será oferecida por instituições especificamente credenciadas pela União.

$\S 2^{\circ}$. A União regulamentará os requisitos para a realização de exames e registro de diplomas relativos a cursos de educação a distância.

$\S 3^{\circ}$. As normas para produção, controle e avaliação de programas de educação a distância e a autorização para sua implementação, caberão aos respectivos sistemas de ensino, podendo haver cooperação e integração entre os diferentes sistemas.

$\S 4^{\circ}$. A educação a distância gozará de tratamento diferenciado, que incluirá:

I - custos de transmissão reduzidos em canais comerciais de radiodifusão sonora e de sons e imagens;

II - concessão de canais com finalidades exclusivamente educativas;

III - reserva de tempo mínimo, sem ônus para o Poder Público, pelos concessionários de canais comerciais.

Rev. GUAL., Florianópolis, v.4, n. 2, p.89-109, mai/ago. 2011 
Esta Lei estabelece a modalidade como válida e equivalente para todos os níveis educacionais, mas não incluiu os setores educacionais de Mestrado e Doutorado, e funcionamento dos cursos exige o credenciamento prévio da instituição feito pelo Governo Federal conseqüentemente pelo Ministério da Educação.

No que diz respeito aos processos de regulação, supervisão e avaliação instituiu-se o decreto 5773, de 2006 (BRASIL, 2010b), onde se define:

Art. $1^{\circ}$ Este Decreto dispõe sobre o exercício das funções de regulação, supervisão e avaliação de instituições de educação superior e cursos superiores de graduação e seqüenciais no sistema federal de ensino.

$\S 1^{\circ} \mathrm{A}$ regulação será realizada por meio de atos administrativos autorizativos do funcionamento de instituições de educação superior e de cursos de graduação e seqüenciais.

$\S 2^{\underline{0}}$ A supervisão será realizada a fim de zelar pela conformidade da oferta de educação superior no sistema federal de ensino com a legislação aplicável.

$\S^{3^{\circ}}$ A avaliação realizada pelo Sistema Nacional de Avaliação da Educação Superior - SINAES constituirá referencial básico para os processos de regulação e supervisão da educação superior, a fim de promover a melhoria de sua qualidade.

O art. 80 da LDB/1996 foi posteriormente regulamentado pelos Decretos 2.494 e 2.561, de 1998, mas ambos substituídos pelo Decreto 5.622, em vigência desde sua publicação em 20 de dezembro de 2005 (BRASIL, 2010a),

O Ministério da Educação tem a preocupação com a qualidade da criação e oferta dos cursos, e sendo assim precisa realizar a regulação, a supervisão e a avaliação através de suas Secretarias específicas, nominalmente a Secretaria de Educação Superior (SESU), a Secretaria de Educação Profissional e Tecnológica (SETEC) e a Secretaria de Educação a Distância (SEED).

Em resumo, os principais processos em $\mathrm{EaD}$ são regulamentados pelos seguintes instrumentos legais, apresentados em ordem cronológica:

- Lei no 9.394, de 20 de dezembro de 1996 (LDB), no art. 80, estabelece que o Poder Público incentivará o desenvolvimento e a veiculação de programas de ensino a distância, em todos os níveis e modalidades de ensino, e de educação continuada.

- Lei $\mathrm{n}^{\mathrm{o}}$ 10.861, de 14 de abril de 2004, institui o Sistema Nacional de Avaliação da Educação Superior (SINAES) e dá outras providências. 
- Decreto $\mathrm{n}^{\mathrm{o}}$ 5.622, de 19 de dezembro de 2005, publicado no Diário Ofícial da União (DOU) de 20.12.2005, regulamenta o art. 80 da LDB/1996, que estabelece as diretrizes e bases da educação nacional. Essa Lei revoga o Decreto ${ }^{\circ} 2.494$, de 10 de fevereiro de 1998, e o Decreto $\mathrm{n}^{\circ} 2.561$, de 27 de abril de 1998.

- Decreto no 5.773, de 09 de maio de 2006, publicado no DOU de 10 de maio de 2006, e dispõe sobre o exercício das funções de regulação, supervisão e avaliação de instituições de educação superior e cursos superiores de graduação e seqüenciais no sistema federal de ensino.

- Decreto no 5.800, de 08 de Junho de 2006, dispõe sobre o Sistema Universidade Aberta do Brasil (UAB), voltado para o desenvolvimento da modalidade de educação a distância, com a finalidade de expandir e interiorizar a oferta de cursos e programas de educação superior no país.

- Portaria Normativa $\mathrm{n}^{\circ}-40$, de 12 de dezembro de 2007, institui o e-MEC, sistema eletrônico de fluxo de trabalho e gerenciamento de informações relativas aos processos de regulação da educação superior no sistema federal de educação.

- Decreto 6.303, de 12 de dezembro de 2007, publicado no DOU em 13 de dezembro de 2007, e altera dispositivos dos Decretos $n^{\circ} 5.622$, de 19 de dezembro de 2005, e Decreto ${ }^{\circ} 5.773$, de 9 de maio de 2006.

- Portaria Normativa $\mathrm{n}^{\mathrm{0}} 23$, de 01 de dezembro de 2010, que altera dispositivos da Portaria Normativa $N^{\circ} 40$, de 12 de dezembro de 2007, que Institui o e-MEC.

Os dispositivos legais apresentados representam as principais ações normativas que regem as atividades de educação a distância no Brasil, tanto na esfera pública como na privada. A utilização dessas bases legais para o desenvolvimento e crescimento da educação a distância é de suma importância, principalmente no que se refere a formação docente, e o acompanhamento por parte do Estado na correta aplicação dessas leis, como também na atualização das mesmos, deve ser conduzido de forma periódica a fim de se proporcionar um ambiente salutar ao surgimento de novas políticas de EaD.

\section{REFERENCIAIS METODOLÓGICOS}

O método de pesquisa é o conjunto das atividades sistemáticas e racionais que, com maior segurança e economia, permite alcançar os objetivos - conhecimento válidos e verdadeiros, de modo a traçar o melhor caminho a ser perseguido, detectando erros e auxiliando as decisões do cientista (LAKATOS, MARCONI, 2004). Neste caso, buscou-se 
alinhar à experiência empírica dos autores no Sistema UAB e CAPES e a teoria que exemplifica os processos relacionados às atividades da $\mathrm{EaD}$.

O estudo proposto caracteriza-se também como descritivo, que segundo Gil (2008) tem como finalidade descrever as características de determinada população ou fenômeno; estabelecendo relações entre variáveis de análise.

A pesquisa quantitativa para Deslandes e Minayo (2008) relaciona-se às estatísticas que visam a criação de modelos abstratos, ou a descrever e explicar fenômenos que produzem regularidades. Já a abordagem qualitativa se aprofunda no mundo dos significados, a partir de uma realidade não visível, que precisa ser exposta e interpretada, em primeira instância, pelos próprios pesquisados. Sendo assim, o trabalho caracteriza-se como quali-quantitativo, em razão das análises e interpretações da realidade estudada, e ainda apresentação de dados quantitativos coletados junto à CAPES, por meio de gráficos e tabelas.

As autoras destacam ainda que estes dois tipos de abordagens e os dados advindos delas não são incompatíveis. Entre elas há uma oposição complementar que, quando bem trabalhada no campo teórico e empírico, produz riqueza de informações, com aprofundamento e fidedignidade interpretativa.

O presente estudo constitui-se em um estudo de caso, que se caracteriza pelo estudo profundo de um ou poucos objetos permitindo um detalhamento sob determinado aspecto ou realidade (GIL, 2008), como é o caso do Sistema Universidade Aberta do Brasil.

Por fim, destaca-se que a análise foi desenvolvida a partir de dados coletados da UAB no que se referem às Instituições de Educação Superior, Pólos Presenciais e Matrículas no período de 2007 a 2011, e coletados através do sistema SISUAB no primeiro semestre de 2011

\section{ANÁLISE DOS DADOS}

A interpretação, explicação e especificação dos dados coletados consistem nos três níveis da elaboração desta análise e, através desses, busca-se fazer as relações necessárias entre os dados obtidos com o estudo proposto e a teoria analisada. Sendo assim, será apresentado o sistema UAB por meio de dados quantitativos que demonstrem a importância do programa no aspecto de formação docente e o acesso a educação superior através da modalidade a distância. 


\subsection{A Universidade Aberta do Brasil - UAB}

O Brasil possui um grande desafio na formação de professores para a educação básica e diante dessa preocupação busca-se desenvolver programas de incentivo à formação de um corpo docente com qualidade e preparado para atender a grande demanda de estudantes carentes de boa educação, e a partir desse cenário é apresentado o Programa Universidade Aberta do Brasil (UAB).

\subsection{Histórico da UAB}

A Universidade Aberta do Brasil foi criada pelo Ministério da Educação no ano de 2005, em parceria com a Associação Nacional dos Dirigentes das Instituições Federais de Ensino Superior (ANDIFES) e Empresas Estatais, no âmbito do Fórum das Estatais pela Educação, com foco nas Políticas e a Gestão da Educação Superior. Trata-se de uma política pública de articulação entre a Secretaria de Educação a Distância (SEED)/MEC e a Diretoria de Educação a Distância (DED)/CAPES, com vistas à expansão da educação superior, no âmbito do Plano de Desenvolvimento da Educação (PDE).

A UAB sustenta-se em cinco eixos fundamentais: expansão pública da educação superior, considerando os processos de democratização e acesso; aperfeiçoamento dos processos de gestão das instituições de ensino superior, possibilitando sua expansão em consonância com as propostas educacionais dos estados e municípios; avaliação da educação superior a distância, tendo por base os processos de flexibilização e regulação implantados pelo MEC; estímulo à investigação em educação superior a distância no país; e financiamento dos processos de implantação, execução e formação de recursos humanos em educação superior a distância.

Os primeiros cursos executados no âmbito da UAB resultaram da publicação de editais. O primeiro edital conhecido como UAB1 foi publicado em 20 de dezembro de 2005 e permitiu a concretização da UAB por meio da seleção para integração e articulação das propostas de cursos, apresentadas exclusivamente por instituições federais de ensino superior, e as propostas de pólos de apoio presencial, apresentadas por estados e municípios.

Na seleção dos pólos e cursos que seriam oferecidos, o Ministério da Educação, por meio da Secretaria de Educação a Distância, divulgou o resultado final do Processo Seletivo de Pólos de Apoio Presencial e de Cursos de Instituições Federais de Ensino Superior (IFES) 
para o Sistema Universidade Aberta do Brasil - UAB, (Edital de Seleção nº1/2005SEED/MEC), de acordo com os pareceres emitidos pelas Comissões de Avaliação in loco, em visitas realizadas nos meses de dezembro de 2006 a março de 2007, para os pólos aprovados e que iniciarão atividades acadêmicas a partir do mês de junho de 2007.

Já o segundo edital, publicado em 18 de outubro de 2006, denominado UAB2, diferiu da primeira experiência por permitir a participação de todas as instituições públicas, inclusive as estaduais e municipais. Ele tinha por objetivo ampliar o Sistema Universidade Aberta do Brasil, instituído pelo Decreto 5.800, de 8 de junho de 2006, visando à democratização, expansão e interiorização da oferta de ensino superior público e gratuito no País, bem como ao desenvolvimento de projetos de pesquisa e de metodologias inovadoras de ensino, preferencialmente para a área de formação inicial e continuada de professores da educação básica.

A oferta dos cursos do UAB2 iniciou no ano de 2008, sendo que o quadro evolutivo da quantidade de cursos ofertados na UAB1 (2007) e UAB2 (2008), além da oferta de 2009 e 2010 são apresentados Figura 1.

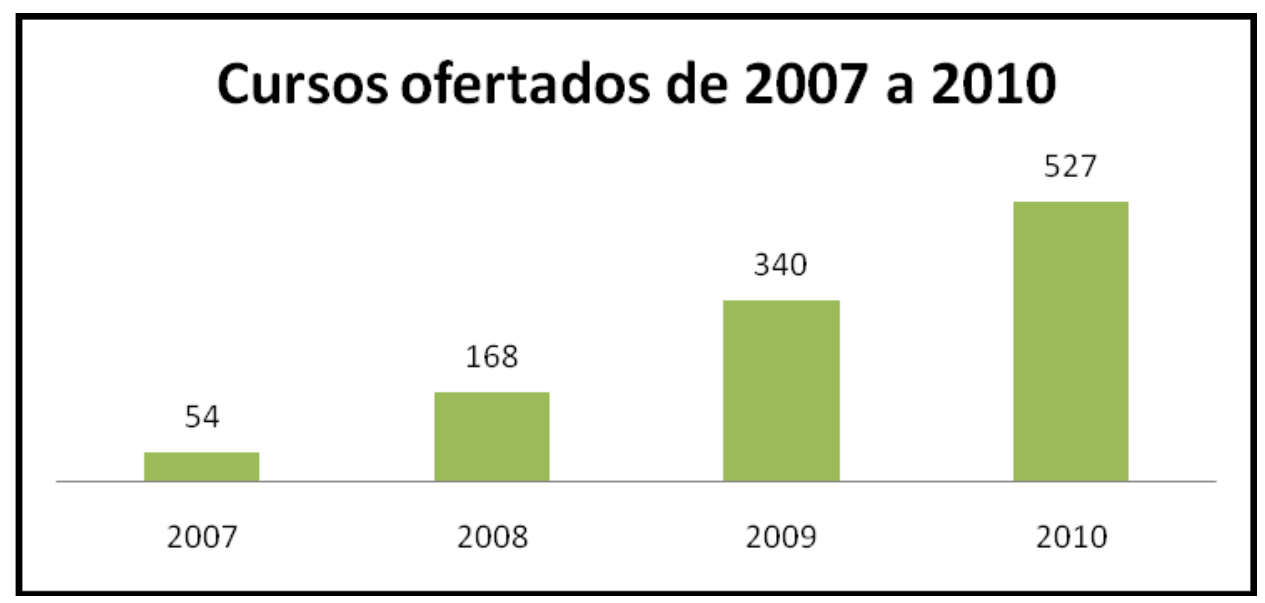

Figura 1 Cursos ofertados de 2007 a 2010. Fonte: SISUAB (2011).

O sistema UAB é entendido como um importante meio de acesso à educação superior no Brasil, a exemplo dos dados apresentados na imagem anterior, e demonstram uma expansão de aproximadamente $1000 \%$ em quatro anos. Considerando somente a oferta de cursos de Licenciatura, que se refere a essência de criação da UAB, os números a seguir 
ressaltam a dimensão da quantidade de cursos de licenciatura no total de cursos ofertados, aproximadamente $40 \%$.

\section{Cursos de Licenciatura no Brasil}

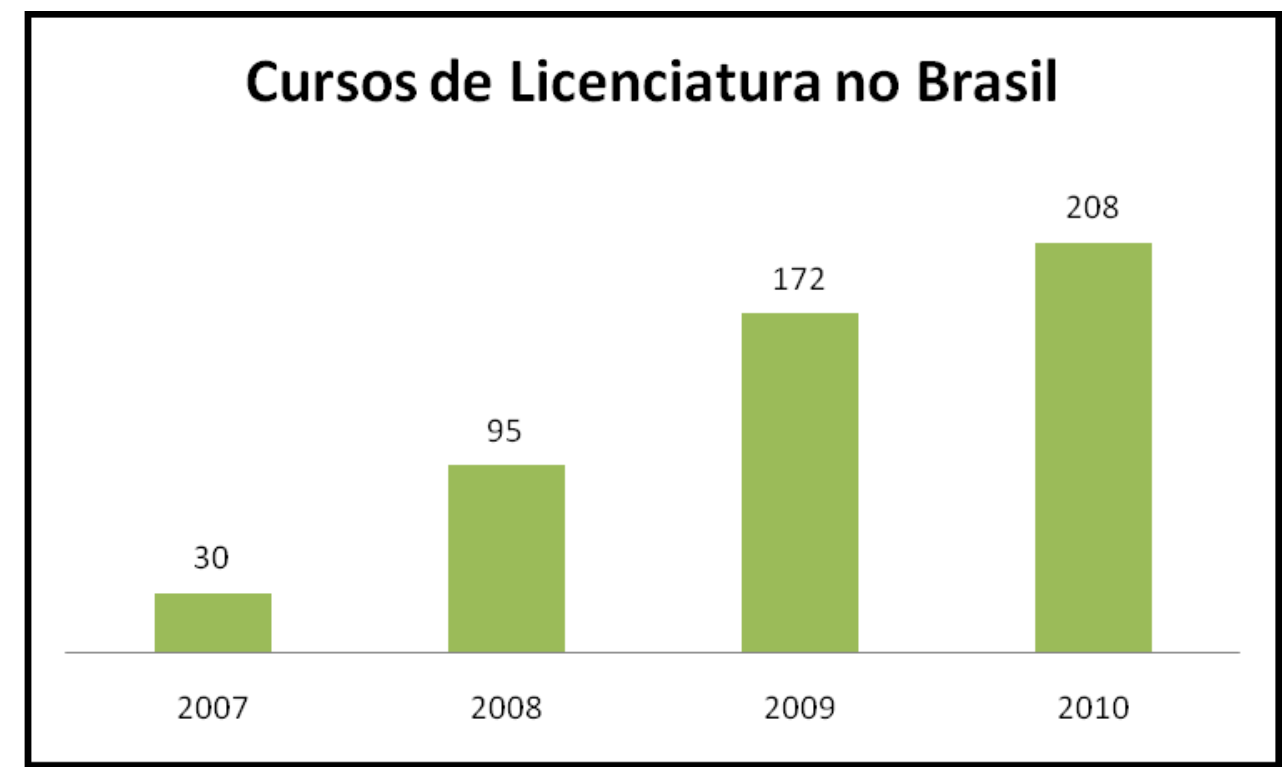

Figura 2 Cursos de Licenciatura no Brasil Fonte: SISUAB (2011).

A oferta dos cursos a distância é realizada essencialmente por intermédio dos Pólos de Apoio Presencial, que são de responsabilidades dos municípios, e eles necessitam de uma infra-estrutura física compatível com as características de cada curso, no intuito de serem credenciados à oferta de cursos a distância. O SINAES e os Referenciais de Qualidade para a Educação a Distância representam os instrumentos norteadores para estruturar um pólo. O quantitativo de pólos credenciados para ofertar cursos a distância no período de 2007 a 2010 estão dispostos na Figura 3.

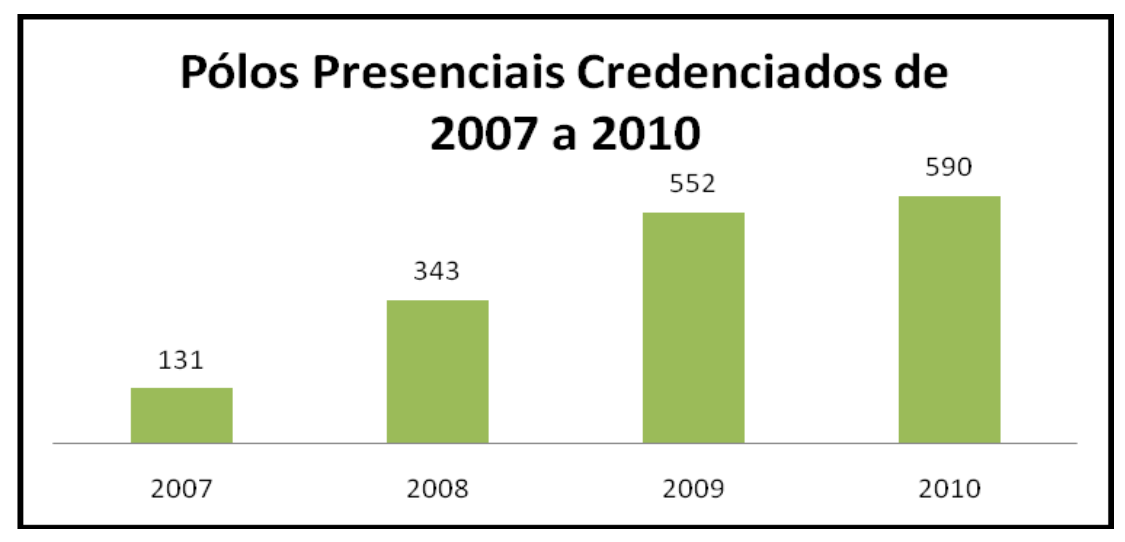

Figura 3 Pólos presenciais credenciados de 2007 a 2010. Fonte: SISUAB (2011). 
Diante dos dados apresentados, que demonstram a evolução da UAB a partir do aumento de cursos e de pólos no período de 2007 a 2010, destaca-se que conjunto de políticas associadas à UAB procuram apoiar a formação de profissionais, principalmente professores, de modo a estruturar parcerias entre municípios e IES e atender demandas locais com objetivo de preparar as pessoas para melhor atuar no mercado de trabalho.

\subsection{A UAB como Sistema}

A Universidade Aberta do Brasil é um sistema integrado por universidades públicas que oferece cursos de nível superior para camadas da população que têm dificuldade de acesso à formação universitária, por meio do uso da metodologia da educação a distância. $\mathrm{O}$ público em geral é atendido, mas os professores que atuam na educação básica têm prioridade de formação, seguidos dos dirigentes, gestores e trabalhadores em educação básica dos estados, municípios e do Distrito Federal.

O Sistema UAB foi instituído pelo Decreto 5.800, de 8 de junho de 2006, para "o desenvolvimento da modalidade de educação a distância, com a finalidade de expandir e interiorizar a oferta de cursos e programas de educação superior no País" (BRASIL, 2010a). Fomenta a modalidade de educação a distância nas instituições públicas de ensino superior, bem como apóia pesquisas em metodologias inovadoras de ensino superior respaldadas em tecnologias de informação e comunicação. Além disso, incentiva a colaboração entre a União e os entes federativos e estimula a criação de centros de formação permanentes por meio dos pólos de apoio presencial em localidades estratégicas (CAPES, 2011).

Assim, o Sistema UAB propicia a articulação, a interação e a efetivação de iniciativas que estimulam a parceria dos três níveis governamentais (federal, estadual e municipal) com as universidades públicas e demais organizações interessadas, enquanto viabiliza mecanismos alternativos para o fomento, a implantação e a execução de cursos de graduação e pósgraduação de forma consorciada. Ao plantar a semente da universidade pública de qualidade em locais distantes e isolados, incentiva o desenvolvimento de municípios com baixo índice de desenvolvimento humano (IDH) e índice de desenvolvimento da educação básica (IDEB). Desse modo, funciona como um eficaz instrumento para a universalização do acesso ao ensino superior e para a requalificação do professor em outras disciplinas, fortalecendo a 
escola no interior do Brasil, minimizando a concentração de oferta de cursos de graduação nos grandes centros urbanos e evitando o fluxo migratório para as grandes cidades.

\subsection{Funcionamento e Fomento da UAB}

O Sistema UAB funciona como articulador entre as instituições de ensino superior e os governos estaduais e municipais, com vistas a atender às demandas locais por educação superior.

Essa articulação estabelece qual instituição de ensino deve ser responsável por ministrar determinado curso em determinado município ou certa microrregião por meio dos pólos de apoio presencial (CAPES, 2011).

Feita a articulação entre as instituições públicas de ensino e os pólos de apoio presencial, o Sistema UAB assegura o fomento de ações, que visam a assegurar o bom funcionamento dos cursos. A Diretoria de Educação a Distância da CAPES fomenta a atuação das instituições públicas de ensino superior (IPES) na oferta de cursos no âmbito da UAB para a realização de:

- produção e distribuição do material didático impresso utilizado nos cursos;

- aquisição de livros para compor as bibliotecas;

- utilização de tecnologias de Informação e Comunicação para interação entre os professores, tutores e estudantes;

- aquisição de laboratórios pedagógicos;

- infra-estrutura dos núcleos de educação a distância nas IPES participantes;

- capacitação dos profissionais envueltos;

- acompanhamento dos pólos de apoio presencial;

- encontros presenciais para o desenvolvimento da EaD.

Estas dimensões representam às áreas que irão assegurar à qualidade de um curso a distância, e, consequentemente, o aprendizado do aluno, sendo o SINAES o instrumento balizador na escolha de alocação dos recursos destinados a operacionalização do curso.

\subsection{Dados da UAB}

A UAB foi criada no intuito de criar as bases para uma universidade aberta e a distância no Brasil e, em conseqüência, oferecer ensino a partir da expansão e interiorização de cursos pelo país (Figura 4), atendendo pessoas que não poderiam almejar a educação presencial (CAPES, 2011). 


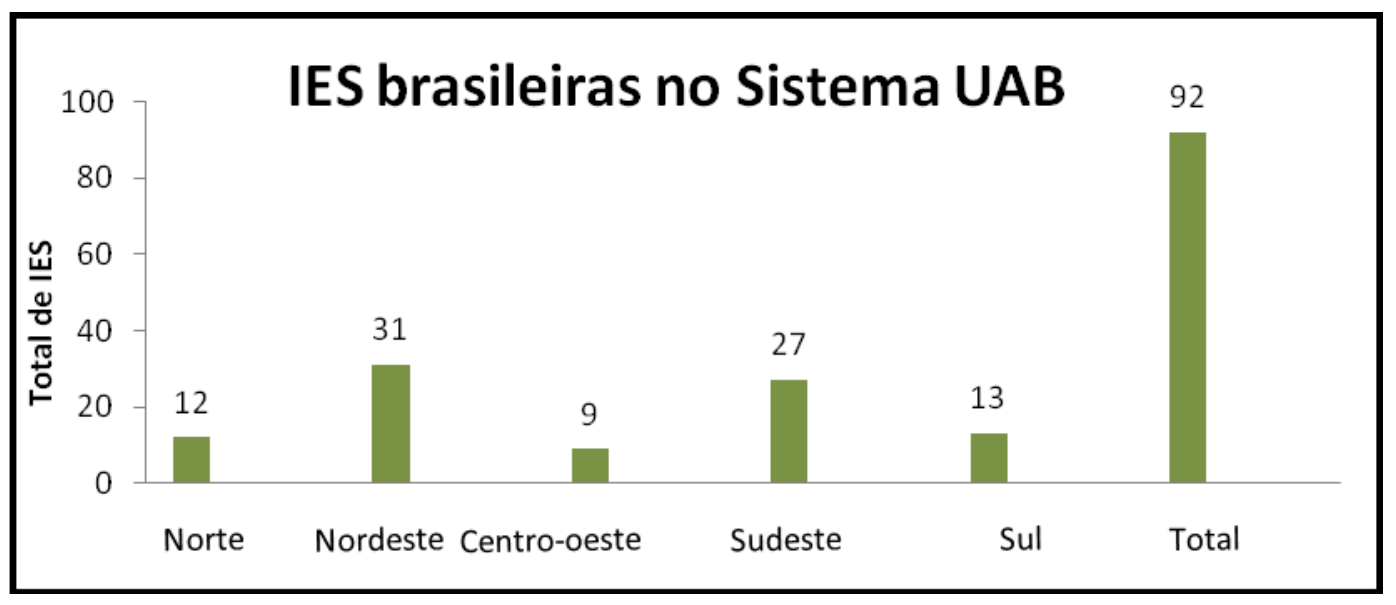

Figura 4 IES brasileira no Sistema UAB Fonte: SISUAB (2011).

Atualmente são 92 instituições (Figuras 4 e 5) que integram o Sistema UAB, entre Universidades Federais, Universidades Estaduais e Institutos Federais de Educação, Ciência e Tecnologia (IFET).

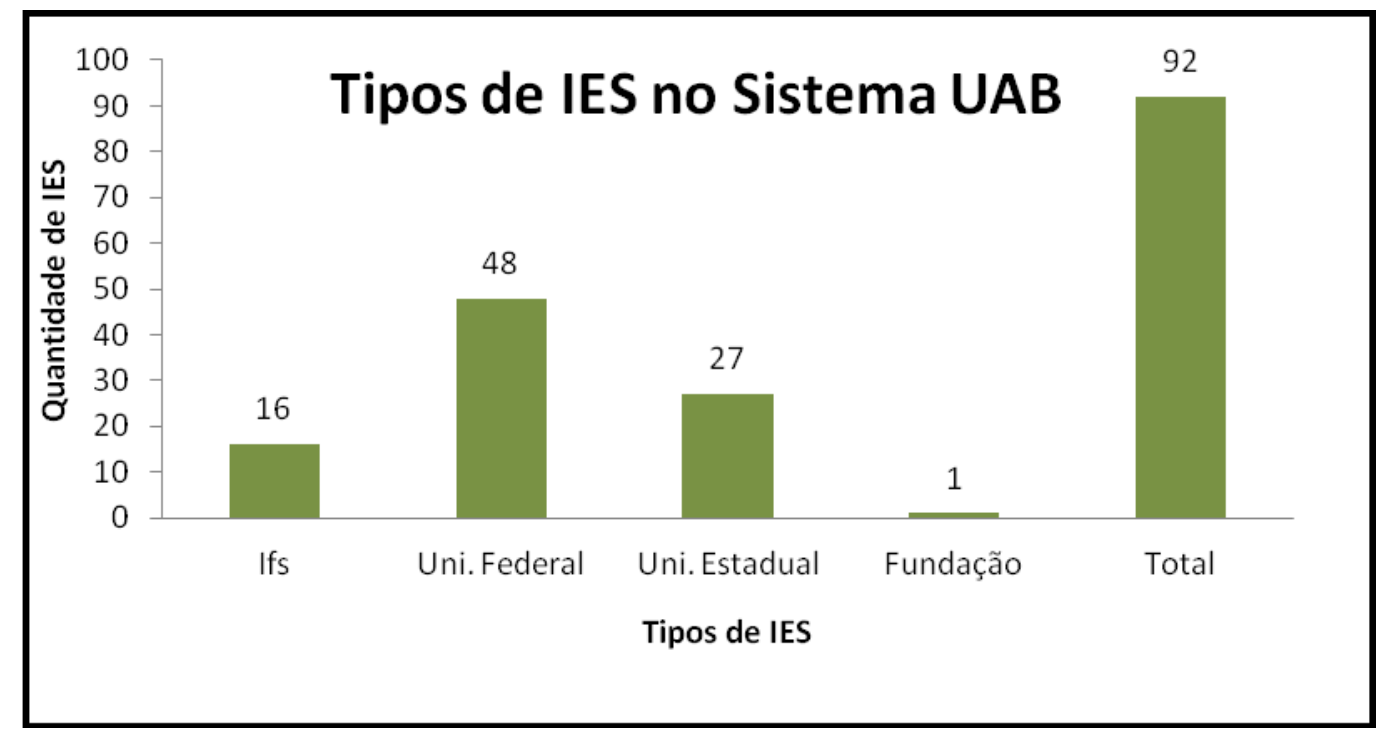

Figura 5 Tipos de IES no Sistema UAB Fonte: SISUAB (2011).

Apresentada a UAB no total de IES inseridas nesse sistema, UAB no Brasil fica é evidenciada também no número de cursos e pólos presenciais em todo o país em 2010, além do número total de matrículas de 2008 a 2010 nos diversos cursos e pólos credenciados (Tabela 1): 
Tabela 1 - Resumo dos pólos, cursos e vagas da UAB

\begin{tabular}{ccccccc}
\hline & & & \multicolumn{5}{c}{ MATRÍCULAS } \\
REGIÃO & $\begin{array}{c}\mathbf{N}^{\mathbf{0}} \mathbf{~ D E} \\
\text { PÓLOS }\end{array}$ & $\begin{array}{c}\mathbf{N}^{\mathbf{0}} \text { DE } \\
\text { CURSOS }\end{array}$ & $\mathbf{2 0 0 8}$ & $\mathbf{2 0 0 9}$ & $\mathbf{2 0 1 0}$ & TOTAIS \\
CENTRO-OESTE & 47 & 63 & 1.928 & 5.463 & 11.609 & 19.000 \\
NORDESTE & 197 & 178 & 9.596 & 31.296 & 51.589 & 92.481 \\
NORTE & 79 & 70 & 3.507 & 6.842 & 10.259 & 20.608 \\
SUDESTE & 157 & 173 & 13.750 & 30.103 & 50.463 & 94.316 \\
SUL & 110 & 123 & 5.955 & 14.379 & 27.147 & 47.481 \\
TOTAL & 590 & 527 & 34.736 & 88.083 & 151.067 & 273.886 \\
\hline
\end{tabular}

Fonte: CAPES (2011)

No Sistema UAB são direcionadas ações que potencializem condições de ampliação do acesso do estudante à educação superior de qualidade, na medida em que amplia os limites geográficos, físicos e financeiros, destacando-se assim os cinco eixos fundamentais do Programa UAB (CAPES, 2011):

- Expansão pública da educação superior, considerando os processos de democratização e acesso.

- Aperfeiçoamento dos processos de gestão das instituições de ensino superior, possibilitando sua expansão em consonância com as propostas educacionais dos estados e municípios.

- Avaliação da educação superior a distância tendo por base os processos de flexibilização e regulação implantados pelo MEC.

- Estímulo à investigação em educação superior a distância no país.

- Financiamento dos processos de implantação, execução e formação de recursos humanos em educação superior a distância.

Para os próximos anos a UAB continuará a apoiar a formação de professores com a oferta de vagas não-presenciais para o Plano Nacional de Formação de Professores da Educação, sendo que essas vagas atenderão a demanda levantada a partir da análise das préinscrições realizadas na Plataforma Freire pelos professores brasileiros, e, além desse apoio, a UAB atenderá a chamada demanda social por vagas de nível superior.

\section{CONSIDERAÇÕES FINAIS}

Considerando a diversidade da população brasileira e a sua dificuldade ou até impossibilidade de acesso às TIC, a educação a distância no Brasil continuará convivendo 
com diferentes abordagens. Diante disso, os gestores educacionais devem buscar mecanismos que democratizem a educação em todos os níveis e modalidades, permitindo a um grande número de pessoas o acesso aos recursos tecnológicos.

Neste contexto, a UAB surge como excelente proposta educacional por permitir às pessoas terem acesso a uma educação superior pública e de qualidade. Sendo assim, o objetivo de grande parte dos programas vinculados a EaD é melhorar a qualidade de ensino, principalmente na educação básica, seja por meio da formação inicial consistente e contextualizada do professor em sua área de atuação ou com a inserção das TIC no ambiente acadêmico dos estudantes.

Para isto, os governos municipais, estadual e federal devem incentivar ainda mais a utilização da $\mathrm{EaD}$ como forma de expansão da formação docente na educação superior nas regiões brasileiras, aproveitando as potencialidades e as experiências das instituições de ensino superior públicas com a modalidade, no caso, por exemplo, utilizando-se das potencialidades do projeto Universidade Aberta do Brasil.

Os diferentes entes da federação devem ainda ser catalisadores também no sentido de incentivar a formação continuada dos professores, focando principalmente na pós-graduação stictu sensu, na qual a maioria dos professores de educação básica não tem acesso, no Brasil, até o momento.

A inserção dos docentes em cursos de mestrado e doutorado pode contribuir para a criação de novos métodos de ensino-aprendizagem, para a ampliação de visão de mundo, e no próprio desenvolvimento de novas competências, habilidades e atitudes que irão refletir no aprendizado do aluno.

\section{REFERÊNCIAS}

ABRAEAD. Anuário Brasileiro Estatístico de Educação Aberta e a Distância. Disponível em: <http://www.abraead.com.br/>. Acesso em: 17 jun. 2010.

ANDIFES, Associação Nacional de Dirigentes das Instituições Federais de Ensino Superior. Proposta de Expansão e Modernização do Sistema Público Federal de Ensino Superior. Brasília, 2003.

ARETIO, Lorenzo Garcia. Educación a distancia hoy. Madrid: Universidad Nacional de Educación a Distancia (UNED), 1996. 
BELLONI, Maria Luiza. Educação a distância. São Paulo: Autores Associados, 2006.

BRASIL. Ministério da Educação. Lei de Diretrizes e Bases da Educação Brasileira LDB Lei 9.394 de 1996.

BRASIL. Ministério da Educação. Decreto $\mathbf{n}^{\mathbf{0}} \mathbf{5 . 8 0 0 / 2 0 0 6}$, que dispõe sobre o Sistema Universidade Aberta do Brasil. Disponível em: $<$ http://www.mec.gov.br $>$. Acessado em: 6 jun. 2010a.

BRASIL. Ministério da Educação. Decreto n ${ }^{\mathbf{0}}$ 5.622/2005, que Regulamenta o art. 80 da Lei no 9.394, de 20 de dezembro de 1996, que estabelece as diretrizes e bases da educação nacional. Disponível em: <http://www.mec.gov.br>. Acessado em: 6 jun. 2010b.

CAPES. $U A B$ - Universidade Aberta do Brasil. Disponível em:

$<$ http://www.uab.capes.gov.br/index.php>. Acessado em: 17 mar. 2011.

CASTRO, Jorge Abrahão de; AQUINO, Luseni Maria C. de; ANDRADE, Carla Coelho de. Juventude e políticas sociais no Brasil. Brasília, IPEA, 2009.

GUIMARÃES, Valter Soares. Formação de Professores: saberes, identidade e profissão. 3 ed. Campinas: Papirus, 2004.

LAKATOS, Eva Maria; MARCONI, Marina de Andrade. Metodologia científica: ciência e conhecimento científico, métodos científicos, teoria, hipóteses e variáveis, metodologia jurídica. São Paulo: Atlas, 2004.

LITWIN, Edith. Educação a distância: temas para o debate de uma nova agenda educativa. Porto Alegre: Artmed, 2001.

MOORE, Michael G.; KEARSLEY, Greg. Educação a distância: uma visão integrada. Traduzido por Roberto Galman. São Paulo: Thomson Learning, 2007.

MORAES, Maria Candida. Informática Educativa no Brasil: uma história vivida, algumas lições aprendidas. Disponível em:

$<$ http://edutec.net/textos/alia/misc/edmcand1.htm>. Acessado em: Abr. de 2010.

NISKIER, Arnaldo. Educação à Distância: a tecnologia da esperança. São Paulo: Loyola, 2000.

OILO, Didier. De lo tradicional a lo virtual: las nuevas tecnologías de la información. Paris: UNESCO, 1998.

PIMENTA, Selma Garrido; ANASTASIOU, Léa das Graças Camargos. Docência no ensino superior. 2 ed. São Paulo: Cortez, 2005.

PRETI, Oreste. Educação a Distância: fundamentos e políticas. Cuiabá: EdUFMT, 2009. 
REZENDE, Flávia Amaral. Características do ambiente virtual construcionista de ensino e aprendizagem na formação de professores universitários. 2004. Dissertação (Mestrado em Multimeios). Instituto de Artes. Universidade Estadual de Campinas, Campinas, 2004. Disponível em:

$<$ http://www.iesalc.unesco.org.ve/documentosinteres/brasil/caracteristicas\%20del\%20aprendi zaje\%20virtual \%20-\%20Flavia\%20Amaral\%20Lazende.pdf $>$. Acessado em: 25 jun. 2010.

SISUAB. Sistema com banco de dados da Universidade Aberta do Brasil. Disponível em: $<$ http://www.uab.capes.gov.br/sisuab>. Acessado em: 07 abr. 2011.

SOUSA, Eda Coutinho B. Machado de. Panorama internacional da educação a distância. In: Em Aberto, Brasília, n.70, p 9-16, abr-jun. 1996.

VIANNEY, João; BARCIA, Ricardo Miranda; LUZ, Rodolfo Joaquim Pinto da. Universidade Virtual: oportunidade de crescimento ou ameaça para as instituições de ensino superior? In: Revista Estudos. n. 26. ago. 2006. Disponível em:

$<$ http://www.abmes.org.br/Publicacoes/Estudos/26/vianney.htm>. Acesso em: 16 maio 2010. 


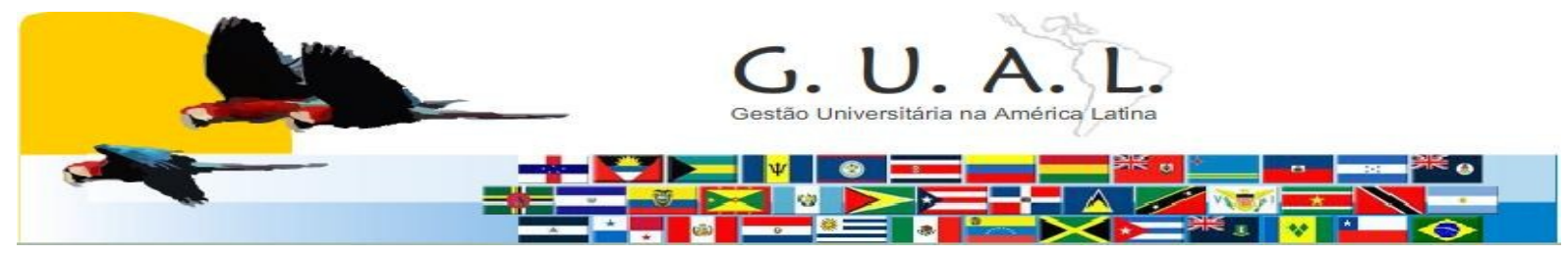

ISSN 1983-4535

\title{
DISTANCE EDUCATION AND TEACHER TRAINING: THE OPEN UNIVERSITY SYSTEM OF BRAZIL AS A MEANS OF PROMOTING THE HIGHER EDUCATION
}

Rafael Pereira Ocampo Moré, Bacharel Universidade Federal de Santa Catarina - UFSC rafael@cse.ufsc.br

Grace Tavares Vieira, Especialista

Coordenação de Aperfeiçoamento de Pessoal de Nivel Superior - CAPES

grace.vieira@capes.gov.br

Marcia Santiago de Araujo, Doutora

Universidade Federal do Rio Grande - FURG

marcia.araujo@riogrande.ifrs.edu.br
Thiago Luiz de Oliveira Cabral, Graduando Universidade Federal de Santa Catarina - UFSC cabral.thi@gmail.com

Alexandre Marino Costa, Doutor

Universidade Federal de Santa Catarina - UFSC

marino@cse.ufsc.br

\begin{abstract}
The Law of Directives and Bases of Education, 1996, article 80 established the legal basis for operation of Distance Education - Distance Education in all instances. The importance of this law stems from the need to conceive with certainty, establish operating parameters and quality and finally, evaluate the various courses of distance education for him indoors. In this scenario arises the Open University of Brazil - UAB as an important policy to combat the deficiency in the training of teachers in the Federation units more remote from major centers, understanding the quality of teacher training is a critical point for the serious deficiencies that plague the basic education Brazil. Therefore, the objective is to analyze the UAB as an alternative to expansion and internalization of education, particularly with regard to teacher training.
\end{abstract}

Keywords: Open University of Brazil. Teacher's training. Expansion. 